\title{
TRIBURIO VOŽTUVO NESANDARUMAS: ETIOLOGIJA, ŠIUOLAIKINĖS DIAGNOSTIKOS IR GYDYMO GALIMYBE்S
}

\author{
Justas Krištopaitis, Tautvydas Joteika, Žilvinas Paškevičius \\ Lietuvos sveikatos mokslu universtiteto Medicinos akademijos Medicinos fakultetas
}

Raktažodžiai: triburio vožtuvo nesandarumas, širdies operacija, vožtuvinè širdies liga, perkateterinè intervencija.

\begin{abstract}
Santrauka
Triburio vožtuvo nesandarumas (TVN) - kardiologijoje itin svarbi, tačiau dažnai primirštama širdies vožtuvų yda, kuriai būdinga grižtamoji kraujo tèkmè iš dešiniojo skilvelio ị dešinijji prieširdị. TVN pagal etiologiją klasifikuojamas ị pirminị (organinị), antrinị (funkcinị) ir izoliuotą. Triburio vožtuvo nesandarumas dažnai yra šalutinis rutininės echokardiografijos atradimas. Pirmos eilès ir plačiausiai naudojami diagnostiniai metodai TVN patvirtinti ir jo sunkumo laipsniui nustatyti yra transtorakalinė bei perstemplinė echokardiografija, bet auksiniu standartu laikomas širdies magnetinio rezonanso tyrimas. Mažo laipsnio TVN laikomas gerybine patologija, tačiau vidutinio ar didelio intensyvumo TVN susijęs su padidèjusia miokardo pažaidos bei neigiamos baigties rizika. Nepaisant šių duomenų, nedaugeliui pacientų, kuriems nustatytas reikšmingas TVN, atliekama operacija. Tradicinis mokymas, kad funkcinis TVN išnyksta, jei sékmingai gydoma pagrindiné liga, yra neteisingas. Daugejjant pacientų, kuriems atliekama perkateterinė kairiujų širdies vožtuvų korekcija, funkcinio TVN perkateterinių gydymo metodų kūrimas ịgavo pagreitį. Daugybė perkateterinių prietaisų šiuo metu yra ankstyvoje klinikinių tyrimų fazejje, kurių ankstyvi rezultatai yra daug žadantys ir gali iš esmès pakeisti didelès rizikos pacientų TVN gydymo galimybes. Šiame straipsnyje apžvelgiami dažniausi TVN etiologiniai veiksniai, šiuolaikinès diagnostikos galimybès, naujausios gydymo gairès ir ateities perspektyvos.
\end{abstract}

\section{Ivadas}

Triburio vožtuvo nesandarumas (TVN) - kardiologijoje itin svarbi, tačiau dažnai primirštama širdies vožtuvų yda, kuriai būdinga grižtamoji kraujo tèkmè iš dešiniojo skilvelio ị dešiniji prieširdị. Dẻl pernelyg mažo dèmesio, triburis vožtuvas (TV) kartais dar vadinamas ,užmirštuoju vožtuvu“ [1-3].
TVN pagal etiologiją skirstomas ị pirminị (organinị) ir antrinị (funkcinį). Būtent pastarasis yra ypač dažna kardiologine patologija, kurios paplitimas siekia $65-85$ proc. bendrosios populiacijos [4,5]. Vakarų šalyse iki 90 proc. pacientų, turinčių vidutinį ar sunkų TVN, nesandarumo priežastis yra kairiosios širdies ligos ar kitos plautinę hipertenziją galinčios sukelti būklès [3]. Dažniausiai TVN būna lengvo ar vidutinio sunkumo, kliniškai nepasireiškia. Pirmos eilès diagnostiniai metodai patvirtinti TVN ir nustatyti jo sunkumo laipsni yra transtorakaline bei perstemplinè echokardiografija, širdies magnetinio rezonanso tyrimas. Nors funkcinis TVN dažnai gydomas konservatyviai, išsiplètus triburio vožtuvo žiedui, prireikia chirurginès intervencijos, siekiant užkirsti kelią ligos progresavimui ir nepalankiai baigčiai [6-8]. Šiame straipsnyje apžvelgiama literatūra, nagrinejjanti TVN etiologinius veiksnius, šiuolaikinès diagnostikos bei gydymo galimybes ir ateities perspektyvas.

Darbo tikslas - remiantis naujausiais moksliniais pasiekimais, literatūros duomenimis, apžvelgti dažniausius triburio vožtuvo nesandarumo etiologinius veiksnius, šiuolaikines diagnostikos galimybes, naujausias TVN gydymo gaires bei ateities perspektyvas.

\section{Tyrimo objektas ir metodai}

Tyrimo objektas - nagrinejama tema mokslinèse duomenų bazèse paskelbtose publikacijose. Paieška buvo atliekama $2020 \mathrm{~m}$. sausio-gegužès mènesiais 5 mokslinèse duomenų bazėse: ScienceDirect, PubMed, UpToDate, SpringerLink, ClinicalKey. Peržiūrètos naujausios triburio vožtuvo nesandarumo mokslinès publikacijos, kuriose aprašoma etiologija, diagnostika, chirurginiai ir perkateteriniai gydymo metodai. Taikyti nuoseklūs publikacijų analizès metodai, remiantis sisteminès literatūros apžvalgos ir metaanalizès kontroliniu sąrašu.

\section{Rezultatai}

TVN etiologija klasifikuojama atsižvelgiant ị pirminę TV patologiją: pirminis (organinis) TVN, susijusią kairio- 
sios širdies ligą - antrinis (funkcinis) TVN arba prieširdžių virpejjimą (PV), nesant susijusių kairiosios širdies ligų izoliuotas TVN. Pirminis TVN sudaro 8-10 proc., antrinis yra vyraujantis TVN mechanizmas ir sudaro daugiau nei 90 proc. visų nustatytų atvejų. Literatūroje izoliuotas TVN vis dažniau pripažistamas kaip atskiros etiologijos liga [9].

Pirminis (organinis) TVN. Pirminį TVN sukelia ịgimtos ar igytos TV ir (ar) jo povožtuvinio aparato (triburių lapelių, chordų, papilinių raumenų arba žiedo) anomalijos. Igyto pirminio TVN priežastys yra navikai (karcinoidinè liga, miksoma), vaistų sukeltas burių pažeidimas (dopamino agonistai, anorektiniai vaistai), jatrogeniniai pažeidimai (endomiokardo biopsija), endokarditas, sisteminès ligos (raudonoji vilkligè, sarkoidozè), radiacija, reumatinès ligos ir traumos [10]. Viena dažniausių igyto pirminio TVN etiologijų - elektrokardiostimuliatoriaus (EKS) endokardiniai laidai, einantys per TV angą. EKS laidas gali tiesiogiai paveikti vieno ar kelių burių judejjimą, trukdyti povožtuviniam aparatui, perforuoti bures, neleisti joms tinkamai užsidaryti. Didejant bendrajam pacientų, turinčių EKS arba implantuojamą kardioverterị defibriliatorių (IKD), skaičiui, TVN paplitimas netolimoje ateityje gali ženkliai išaugti. Atliekant retrospektyvinius tyrimus nustatyta, kad po EKS implantavimo iki 38 proc. pacientų per 1-1,5 metų gali išsivystyti didelis TVN [11]. Viena iš dažniausių igimtų TVN priežasčių yra Ebšteino anomalija, kuriai tipiškai būdingas burių poslinkis viršūnès link, kylantis tiesiai iš dešiniojo skilvelio (DS) sienos, be identifikuojamų chordų [12].

Antrinis (funkcinis) TVN pirmiausiai atsiranda dèl TV žiedo išsiplètimo, DS dilatacijos ir disfunkcijos, sukeliančios TV anatomijos ir funkcijos anomalijas [9]. Funkcinis TVN dažniausiai yra antrinis dẻl kairiosios širdies vožtuvinių ir miokardo ligų, kurie sukelia plaučių hipertenziją (PH), padidejjusị DS pokrūvị bei DS remodeliaciją. Dažniausios kairiosios širdies vožtuvų ligos, kurios gali sukelti TVN didelis mitralinio vožtuvo nesandarumas (MVN) ir aortos stenozė (AS) (atitinkamai TVN išsivyste $25 \%$ ir $40 \%$ pacientų) $[13,14]$. Svarbu pastebèti, kad prieširdžių virpejjimas, ypač lètinis, gali būti svarbus TVN vystymosi etiologinis veiksnys, visų pirma, dèl jo ịtakos TV žiedo išsiplètimui [15]. Gerèjant MV ligų diagnostikai, pastebèta, kad mažaug 30-50 proc. pacientų, turinčių sunkų MVN, pasižymi reikšmingu TVN [16]. Be to, pacientams, kuriems išsivysto $\mathrm{PH}$ dèl kairiosios širdies ligų ar kitos etiologijos, dažnai išsivysto DS išsiplètimas ir disfunkcija, todèl gali atsirasti TV žiedo dydžio anomalijos, TV burių prisitvirtinimo anomalijos, kurios taip pat gali sukelti didelį TVN [17].

Izoliuotas TVN dažniausiai nustatomas senyvo amžiaus pacientams, kurių dažnas PV, tuo metu nesant PH ar gretutinès kairiosios širdies ligos. Pagrindinis mechanizmas yra ryškus dešiniojo prieširdžio (DP) ir TV žiedo išsiplètimas, sukeliantis netinkamą burių susiglaudimą, jei nèra DS remodeliacijos [18-20].

TVN diagnostika. TVN diagnozuojamas derinant klinikinius ir radiologinius tyrimų duomenis. Lengvo ar vidutinio laipsnio TVN dažniausiai kliniškai nepastebimas. Esant sunkiam TVN, klinikiniai simptomai gali nepasireikšti, bet kartais stebima dešiniosios širdies nepakankamumo klinikinè išraiška: ascitas, edemos kojose ar hepatomegalija. Viena svarbiausių objektyvios apžiūros dalių yra širdies auskultacija. TVN būdingas holosistolinis ūžesys, geriausiai girdimas ties kairiaja apatine krūtinkaulio dalimi, ypač ịkvejpimo metu, tačiau šis požymis taip pat nèra itin dažnas [1].

Daug dažniau TVN diagnozė nustatoma, atlikus echokardiografiją. Plačiausiai naudojama dviejų dimensijų (2D) echokardiografija, tačiau labiau pažengęs yra trijų dimensijų (3D) echokardiografinis tyrimo metodas, leidžiantis dar objektyviau ir tiksliau ịvertinti TV anatomiją ir funkciją, taip sumažinantis netikslų radiologinių vaizdų interpretavimą [21]. Esant TVN, echokardiografijos metu, pasitelkiant Doplerio režimą, stebima grį̌tamoji kraujo srove TV. Šio režimo duomenys tinkamesni diagnozès nustatymui, nei TVN sunkumo laipsnio vertinimui. Matuojamas ir vena contracta (VC) plotis. Didesnis nei $7 \mathrm{~mm}$ matmuo leidžia įtarti sunkaus laipsnio MVN, kai mažesnių reikšmių vertinimas yra sunkesnis ir nevienareikšmis [22,23]. Esant galimybei, vertinamas vienodo kraujotakos greičio puslankio spindulys (angl. proximal isomelosity surface arena, PISA), kuris gali būti naudojamas vertinant TVN sunkumo laipsnị. Stipriausiu specifiniu papildomu echoskopiniu parametru diagnozuojant sunkaus laipsnio TVN laikoma priešinga kraujo srovès kryptis kepenų venoje sistolès metu. Kiti echokardiografiniai duomenys TVN diagnostikoje yra dešiniujų širdies kameru prasiplètimo matmenys, dilatuota apatinè tuščioji vena (ATV), išsiplètę koronariniai sinusai ir tarpskilvelinès pertvaros poslinkis link kairiosios širdies pusès [22,24].

Kitas medicinineje praktikoje naudojamas tyrimas yra perstemplinè echokardiografija. Šis metodas taikomas tada, kai transtorakalinè echokardiografija nepakankamai informatyvi [1]. Nors plačiausiai TVN diagnostikoje naudojami echoskopiniai tyrimo metodai, širdies magnetinio rezonanso tyrimas (ŠMRT) laikomas auksinu standartu, vertinant dešiniosios širdies kamerų matmenis ir funkciją. Šio tyrimo pagalba TV ir dešiniujų širdies kamerų vizualizacija yra ypač detali dèl galimybès vaizdus vertinti keliose plokštumuse. MRT privalumas - apšvitos pacientui nebuvimas [25-28].

Dešiniosios širdies kateterizavimas šiuo metu medicininejje praktikoje pasitelkiamas labai retai. Tiesa, jis pasitarnauja planuojant antrinio TVN chirurginį gydymą, siekiant ivertinti plautinès arterijos hemodinaminius rodiklius [29]. 
Funkcinio TVN farmakoterapija. Pacientams, kurie turi vidutinio arba didelio laipsnio TVN, klinika pasireiškia vèlai fizinio krūvio netoleravimu bei kitais DS nepakankamumo simptomais, kuriuos yra sunku gydyti farmakoterapija. Funkcinio TVN diagnostika ir gydymas orientuotas ị pagrindinès jị sukèlusios priežasties identifikavimą ir jos šalinimą. Pacientai, kuriems nustatyta išeminè ar neišeminès kilmès kardiomiopatija, gydomi remiantis dabartinèmis širdies nepakankamumo rekomendacijomis [30]. Jei yra klinikinis įtarimas dèl $\mathrm{PH}$, būtina atlikti papildomą diferencinę diagnostiką - dešiniosios širdies kateterizaciją, kad būtų galima nustatyti pacientus, kuriems gali būti naudinga specifine farmakoterapija (pavyzdžiui, kalcio kanalų blokatoriais, endotelino receptorių antagonistais, fosfodiesterazès 5 inhibitoriais, prostaciklino sintetiniais analogais, prostaciklino receptorių agonistais) [17,31]. Pacientams, kuriems dèl pakartotinès plaučių embolijos išsiplètė dešinysis skilvelis, turètų būti pradèta terapija antikoaguliantais [17,31], tačiau daugeliui TVN gydymo galimybès vaistais yra ribotos. Pagrindiné priežastis, sunkinanti farmakoterapijos optimizavimą - prastējanti inkstų funkcija, kuri riboja tolesni diuretikų dozės didinimą, siekiant sumažinti perkrovos tūriu simptomus. Jei inkstų funkcijos nepakankamumas neišsivystè, galima pridèti aldosterono receptorių antagonistus [31]. Literatūroje nèra patvirtintų klinikinių tyrimų, ịrodančių aldosterono antagonistų, angiotenziną konvertuojančių fermentų inhibitoriu (AKF) ar angiotenzino II receptorių blokatoriu (ARB) teigiamą poveikị dešiniojo skilvelio rekonstrukcijai ir paciento funkciniam pajègumui.

Dabartinès funkcinio TVN chirurginès gydymo indikacijos. Dabartinèse vožtuvinių širdies ligų gydymo gairèse pateiktos chirurginio gydymo rekomendacijos, atsižvelgiant i TVN etiologiją, DS funkciją, TVN sunkumo laipsnị [32,33]. Literatūros duomenimis, daugiausiai dèmesio susilaukia perkateteriniai TVN gydymo metodai, o intervenciniai vis dar yra ankstyvojoje klinikinių tyrimų fazeje [34]. Optimalus TVN chirurginès intervencijos laikas yra kontraversiškas [35]. Nepaisant to, chirurginè intervencija neturètų būti atidèta, nes vystosi negrịžtamas DS pažeidimas, organų nepakankamumas, o gydymo rezultatai yra prastesni po vẻlyvos chirurginès intervencijos [36]. Naujausiose rekomendacijose TV operacija rekomenduojama pacientams, kuriems atliekama kairiosios širdies vožtuvų operacija, esant didelio laipsnio TVN (I klasės rekomendacijos, įrodymų lygmuo C) ir (arba) TV žiedas viršija $40 \mathrm{~mm}$ arba $21 \mathrm{~mm} / \mathrm{m}^{2}$ esant vidutinio (didelio) laipsnio TVN (IIa klasės rekomendacijos, irodymų lygmuo C) [30]. Pastaroji rekomendacija pateisina TV chirurginę operaciją pacientams, sergantiems vidutinio sunkumo arba net mažo laipsnio TVN, esant TV žiedo išsiplètimui. TV operacija gali būti svarstoma pacien- tams, kuriems atliekama kairiosios širdies vožtuvų operacija esant mažo (vidutinio) laipsnio TVN, net nesant TV žiedo išsiplètimo, jei prieš tai buvo dokumentuotas DS nepakankamumas (II b klasès rekomendacijos, ịrodymų lygmuo C) [30]. Gairèse pateikiamos II a klasès (irrodymų lygmuo C) rekomendacijos dèl TV operaciju pacientams, turintiems didelio laipsnio TVN po buvusios kairiosios širdies vožtuvų operacijos, jei jiems pasireiškia širdies nepakankamumo (ŚNN) simptomai arba akivaizdžiai progresuoja DS dilatacija ir disfunkcija [30]. Prieš priimant sprendimą pakartotinai operuoti TV, turi būti atmestos šios būklès: sunki dešiniojo ir kairiojo skilvelio disfunkcija, didelio laipsnio PH, kitos sunkios plaučių kraujagyslių ligos.

Funkcnio TVN chirurginio gydymo galimybès. Pacientams, kurie atitinka anatominius reikalavimus, nesutrikusi DS funkcija, priklauso mažos chirurginès rizikos grupei, turètų būti teikiama pirmenybė vožtuvą tausojančiai operacijai [37]. TV anuloplastikos operacija siekiama paveikti patofiziologinę funkcinio TVN grandi - išsiplètusį TV žiedą. Nuo septintojo dešimtmečio buvo aprašyti keli chirurginès anuloplastikos metodai - plastika siūlu, žiedu arba juostele (Kay procedūra, De Vega annuloplastika). Šiuo metu, atliekant TV anuloplastiką, dažniausiai naudojami mažesnių matmenų rigidiški, pusiau rigidiški ir lankstūs žiedai arba lanksčios juostelès [35]. Rigidiško arba pusiau rigidiško žiedo implantacija mažiau rizikinga vèlyvam, pasikartojančiam TVN, lyginant su anuloplastika lanksčia juostele, tačiau didesnè žiedo atkryčio rizika [38]. Anuloplastiniai žiedai ar juostelès neuždengia viso TV žiedo, bet lieka atvira TV žiedo pertvaros dalyje, kad būtų išvengta pažaidų širdies laidžiajai sistemai (ŠLS). Pastaraisiais metais buvo sukurti triburio vožtuvo anuloplastiniai žiedai, primenantys natyvinio TV žiedo sudètingą trimatę konfigūraciją [39]. Atliktos retrospektyvios analizės metu nustatyta, kad anuloplastika žiedu yra pranašesnè už anuloplastiką siūlu - geresnis pacientų išgyvenamumas, mažesnis pakartotinių operacijų skaičius, mažesné pasikartojančio TVN rizika [39]. Nors literatūroje pristatoma vis daugiau tyrimų, susijusių su TVN gydymu, tačiau TVN gydymas pasirenkant anuloplastiką žiedu (rigidiskas ar lankstus) vis dar diskusijų lygmenyje.

Kartais TV plastinè korekcija negalima, todèl TV protezuojamas. TV protezavimas turètų būti svarstomas, kai vožtuvo plastika yra techniškai neįmanoma arba prognozuojama nepatvari konstrukcija (pavyzdžiui, išreikšta DS remodeliacija ar disfunkcija, didelè PH). Literatūros duomenimis, atliekant TV protezavimą, biologinių ir mechaninių vožtuvų ilgalaikè baigtis yra panaši [40]. Atsižvelgiant ị mažesnę tromboembolijos riziką, daugelis chirurgų pasirenka biologinius vožtuvus, tačiau TV protezavimas turi būti individualizuotas, remiantis paciento amžiumi, funk- 
cine būkle, gretutinèmis širdies ir kitų sistemų ligomis [39].

Inovatyvios perkateterinės funkcinio TVN gydymo galimybès. Nepaisant didejjančių TV procedūrų skaičiaus per pastaraji dešimtmetį, izoliuotos TV operacijos atliekamos retai ir kasdienejje praktikoje siejamos su viena iš didžiausių rizikų tarp visų širdies vožtuvų operacijų. Dèl šios priežasties atsirado daugybẻ negydytų TVN atvejų. Atsižvelgiant ị tai, atsirado keletas mažiau invazyvių perkateterinių gydymo metodų kaip alternatyva operacijai didelès rizikos pacientams, turintiems funkcinị TVN [41]. Dabartinius perkateterinius TVN gydymo metodus galima suskirstyti ị tris grupes, atsižvelgiant i jų veikimo mechanizmą: anuloplastiniai, koaptacijos prietaisai, heterotopinis kavalinio vožtuvo implantavimas (CAVI). Tikimasi, kad būsimaisiais metais rasis vis daugiau inovatyvių transkateterinių gydymo metodų, o ịgijus daugiau patirties šioje srityje - pagerès procedūrų efektyvumas bei klinikiniai rezultatai. Nepaisant to, optimalus perkateterinès intervencijos laikas, perkateteriniu prietaisu patvarumas ir ilgalaikès klinikinès baigtys turètų būti pagrindinis tolimesnių mokslinių tyrimų tikslas.

\section{Rezultatų aptarimas}

TVN farmakoterapijos pasirinkimo galimybès yra ribotos. TV chirurginè korekcija neturètu būti atidedama, nes vidutinio ar didelio intensyvumo TVN yra susijęs su padidèjusia miokardo pažaidos bei nepalankios baigties rizika. TV korekcija turi būti atliekama vadovaujantis naujausiomis vožtuvinių širdies ligų rekomendacijomis [29]. Šiuo metu atliekami ịvairių perkateterinių prietaisų klinikiniai tyrimai, kurie leis pasiūlyti alternatyvų gydymo metodą didelès chirurginès rizikos pacientams. Nepaisant daug žadančių ankstyvų duomenų apie perkateterinių prietaisų saugą ir efektyvumą, tolimesnès studijos yra būtinos, kad būtų nustatytos galimos klinikinès baigtys bei ilgalaikis poveikis TV funkcijai. Senyvo amžiaus pacientu gydymo pasirinkimas vaistais ar perkateterinių prietaisų pagalba reikalingas tolimesnių tyrimų.

\section{Išvados}

1. Dažniausias etiologijos veiksnys, sudarantis daugiau nei 90 proc. triburio vožtuvo nesandarumo atvejų, yra funkcinis triburio vožtuvo nesandarumas.

2. Auksinis standartas TVN diagnostikoje - širdies magnetinio rezonanso tyrimas, tačiau klinikinejje praktikoje dažniausiai naudojami diagnostiniai metodai yra transtorakalinė bei perstemplinè echokardiografija.

3. Didelès chirurginès rizikos pacientams turètų būti taikoma medikamentinè terapija, tačiau daugejja perkateterinių gydymo metodų, kurie ateityje gali būti pasiūlyti kaip alternatyvus gydymo pasirinkimas šios grupès pacientams.
4. Didelio ir vidutinio laipsnio triburio vožtuvo nesandarumas turètų būti gydomas chirurginiais vožtuvų korekcijos metodais, remiantis Europos širdies asociacijos pateiktomis gairemis ir rekomendacijomis.

\section{Literatūra}

1. Rodés-Cabau J, Taramasso M, O'Gara PT. Diagnosis and treatment of tricuspid valve disease: current and future perspectives. Lancet 2016;388(10058):2431-2442. https://doi.org/10.1016/S0140-6736(16)00740-6

2. Raman SV, Sparks EA, Boudoulas H, Wooley CF. Tricuspid valve disease: tricuspid valve complex perspective. Curr Probl Cardiol 2002;27(3):103-142.

https://doi.org/10.1016/S0146-2806(02)70012-1

3. Badano LP, Muraru D, Enriquez-Sarano M. Assessment of functional tricuspid regurgitation. Eur Heart J 2013;34(25):1875-1885. https://doi.org/10.1093/eurheartj/ehs474

4. Singh JP, Evans JC, Levy D, Larson MG, Freed LA, Fuller DL, et al. Prevalence and clinical determinants of mitral, tricuspid, and aortic regurgitation (the Framingham Heart Study). Am J Cardiol 1999;83(6):897-902.

https://doi.org/10.1016/S0002-9149(98)01064-9

5. Lavie CJ, Hebert K, Cassidy M. Prevalence and severity of doppler-detected valvular regurgitation and estimation of rightsided cardiac pressures in patients with normal two-dimensional echocardiograms. Chest 1993;103(1):226-231.

https://doi.org/10.1378/chest.103.1.226

6. Lee JW, Song JM, Park JP, Lee JW, Kang DH, Song JK. Longterm prognosis of isolated significant tricuspid regurgitation. Circ J 2010;74(2):375-380.

https://doi.org/10.1253/circj.CJ-09-0679

7. Benedetto U, Melina G, Angeloni E, Refice S, Roscitano A, Comito C, et al. Prophylactic tricuspid annuloplasty in patients with dilated tricuspid annulus undergoing mitral valve surgery. J Thorac Cardiovasc Surg 2012;143(3):632-638.

https://doi.org/10.1016/j.jtcvs.2011.12.006

8. Van de Veire NR, Braun J, Delgado V, Versteegh MI, Dion RA, Klautz RJ, et al. Tricuspid annuloplasty prevents right ventricular dilatation and progression of tricuspid regurgitation in patients with tricuspid annular dilatation undergoing mitral valve repair. J Thorac Cardiovasc Surg 2011;141(6):1431-1439. https://doi.org/10.1016/j.jtcvs.2010.05.050

9. Dreyfus GD, Martin RP, Chan KM, Dulguerov F, Alexandrescu C. Functional tricuspid regurgitation: a need to revise our understanding. J Am Coll Cardiol 2015;65(21):2331-2336.

https://doi.org/10.1016/j.jacc.2015.04.011

10. Adler DS. Non-functional tricuspid valve disease. Ann Cardiothorac Surg 2017;6(3):204-213.

https://doi.org/10.21037/acs.2017.04.04

11. Höke U, Auger D, Thijssen J, Wolterbeek R, van der Velde ET, et al. Significant lead-induced tricuspid regurgitation is 
associated with poor prognosis at long-term follow-up. Heart 2014;100(12):960-8.

https://doi.org/10.1136/heartjnl-2013-304673

12. Paranon S, Acar P. Ebstein's anomaly of the tricuspid valve: from fetus to adult: congenital heart disease. Heart 2008;94(2):237-243.

https://doi.org/10.1136/hrt.2006.105262

13. Généreux P, Pibarot P, Redfors B, et al. et al. Staging classification of aortic stenosis based on the extent of cardiac damage. Eur Heart J 2017;38:3351-8. https://doi.org/10.1093/eurheartj/ehx381

14. Shiran A, Sagie A. Tricuspid regurgitation in mitral valve disease incidence, prognostic implications, mechanism, and management. J Am Coll Cardiol 2009;53(5):401-408. https://doi.org/10.1016/j.jacc.2008.09.048

15. Prihadi EA, Delgado V, Leon MB, Enriquez-Sarano M, Topilsky Y, Bax JJ. Morphologic types of tricuspid regurgitation: characteristics and prognostic implications. JACC Cardiovasc Imaging 2019;12(3):491-499.

https://doi.org/10.1016/j.jcmg.2018.09.027

16. Guérin A, Dreyfus J, Le Tourneau T, Sportouch C, Lairez O, Eicher JC, et al. Secondary tricuspid regurgitation: do we understand what we would like to treat? Arch Cardiovasc Dis 2019;112(10):642-651.

https://doi.org/10.1016/j.acvd.2019.04.010

17. Arsalan M, Walther T, Smith 2nd RL, Grayburn PA. Tricuspid regurgitation diagnosis and treatment. Eur Heart J 2017;38(9):634-638.

https://doi.org/10.1093/eurheartj/ehv487

18. Mutlak D, Lessick J, Reisner SA, Aronson D, Dabbah S, Agmon Y. Echocardiography-based spectrum of severe tricuspid regurgitation: the frequency of apparently idiopathic tricuspid regurgitation. J Am Soc Echocardiogr 2007;20(4):405-408. https://doi.org/10.1016/j.echo.2006.09.013

19. Topilsky Y, Khanna A, Le Tourneau T, Park S, Michelena H, Suri R, et al. Clinical context and mechanism of functional tricuspid regurgitation in patients with and without pulmonary hypertension. Circ Cardiovasc Imaging 2012;5(3):314-323. https://doi.org/10.1161/CIRCIMAGING.111.967919

20. Park JH, Shin SH, Lee MJ, Lee MD, Shim HI, Yoon J, et al. Clinical and echocardiographic factors affecting tricuspid regurgitation severity in the patients with lone atrial fibrillation. J Cardiovasc Ultrasound 2015;23(3):136-142.

https://doi.org/10.4250/jcu.2015.23.3.136

21. Badano LP, Agricola E, Perez de Isla L, Gianfagna P, Zamorano JL. Evaluation of the tricuspid valve morphology and function by transthoracic real-time three-dimensional echocardiography. Eur J Echocardiogr 2009;10(4):477-484.

https://doi.org/10.1093/ejechocard/jep044

22. Lancellotti P, Tribouilloy C, Hagendorff A, Popescu BA, Edvardsen T, Pierard LA, et al. Recommendations for the echocardiographic assessment of native valvular regurgitation: an executive summary from the European association of cardiovascular imaging. Eur Heart J Cardiovasc Imaging 2013;14(7):611-644.

https://doi.org/10.1093/ehjci/jet105

23. Badano LP, Muraru D, Enriquez-Sarano M. Assessment of functional tricuspid regurgitation. Eur Heart J 2013;34(25):1875-1885.

https://doi.org/10.1093/eurheartj/ehs474

24. Gonzalez-Vilchez F, Zarauza J, Vazquez de Prada, J. A., Martín Durán R, Ruano J, Delgado C, et al. Assessment of tricuspid regurgitation by doppler color flow imaging: angiographic correlation. Int J Cardiol 1994;44(3):275-283.

https://doi.org/10.1016/0167-5273(94)90292-5

25. Grothues F, Moon JC, Bellenger NG, Smith GS, Klein HU, Pennell DJ. Interstudy reproducibility of right ventricular volumes, function, and mass with cardiovascular magnetic resonance. Am Heart J 2004;147(2):218-223.

https://doi.org/10.1016/j.ahj.2003.10.005

26. Koskenvuo JW, Järvinen V, Pärkkä JP, Kiviniemi TO, Hartiala JJ. Cardiac magnetic resonance imaging in valvular heart disease. Clin Physiol Funct Imaging 2009;29(4):229-240. https://doi.org/10.1111/j.1475-097X.2009.00865.x

27. Masci PG, Dymarkowski S, Bogaert J. Valvular heart disease: what does cardiovascular MRI add? Eur Radiol 2008;18(2):197-208. https://doi.org/10.1007/s00330-007-0731-x

28. Hahn RT, Thomas JD, Khalique OK, Cavalcante JL, Praz F, Zoghbi WA. Imaging assessment of tricuspid regurgitation severity. JACC Cardiovasc Imaging 2019;12(3):469-490 https://doi.org/10.1016/j.jcmg.2018.07.033

29. Baumgartner H, Falk V, Bax JJ, de Bonis M, Hamm C, Holm PJ, et al. 2017 ESC/EACTS Guidelines for the management of valvular heart disease. Rev Esp Cardiol (Engl Ed) 2018;71(2):110. https://doi.org/10.1016/j.rec.2017.12.013

30. Nishimura RA, Otto CM, Bonow RO, Carabello BA, Erwin JP, et al. 2014 AHA/ACC guideline for the management of patients with valvular heart disease: a report of the American college of cardiology/American heart association task force on practice guidelines. J Thorac Cardiovasc Surg 2014;148(1):e1-e132. https://doi.org/10.1161/CIR.0000000000000029

31. Lankeit M, Keller K, Tschöpe C, Pieske B. Medicinal treatment of tricuspid valve regurgitation. Herz 2017;42(7):634-643. https://doi.org/10.1007/s00059-017-4609-7

32. Antunes MJ, Rodríguez-Palomares J, Prendergast B, de Bonis M, Rosenhek R, Al-Attar N, et al. Management of tricuspid valve regurgitation: position statement of the European Society of cardiology working groups of cardiovascular surgery and valvular heart disease. Eur J Cardiothorac Surg 2017;52(6):1022-1030. https://doi.org/10.1093/ejcts/ezx279 
33. Ponikowski P, Voors AA, Anker SD, Bueno H, Cleland JGF, Coats AJS, et al. 2016 ESC Guidelines for the diagnosis and treatment of acute and chronic heart failure: the task force for the diagnosis and treatment of acute and chronic heart failure of the European Society of cardiology (ESC) developed with the special contribution of the Heart failure association (HFA) of the ESC. Eur Heart J 2016;37(27):2129-2200.

https://doi.org/10.1093/eurheartj/ehw128

34. Hahn RT. State-of-the-art review of echocardiographic imaging in the evaluation and treatment of functional tricuspid regurgitation. Circ Cardiovasc Imaging 2016;9(12):e005332. https://doi.org/10.1161/CIRCIMAGING.116.005332

35. Shumakov DV, Zybin DI, Popov MA. Surgical repair of secondary tricuspid regurgitation. Khirurgiia (Mosk) 2019;(6):88-93. https://doi.org/10.17116/hirurgia201906188

36. Bohbot Y, Chadha G, Delabre J, Landemaine T, Beyls C, Tribouilloy C. Characteristics and prognosis of patients with significant tricuspid regurgitation. Arch Cardiovasc Dis 2019;112(10):604-614. https://doi.org/10.1016/j.acvd.2019.06.011

37. Antunes MJ, Rodríguez-Palomares J, Prendergast B, De Bonis M, Rosenhek R, Al-Attar N, et al. Management of tricuspid valve regurgitation: position statement of the European Society of cardiology working groups of cardiovascular surgery and valvular heart disease. Eur J Cardiothorac Surg 2017;52(6):1022-1030.

https://doi.org/10.1093/ejcts/ezx279

38. Pfannmüller B, Doenst T, Eberhardt K, Seeburger J, Borger MA, Mohr FW. Increased risk of dehiscence after tricuspid valve repair with rigid annuloplasty rings. J Thorac Cardiovase Surg 2012;143(5):1050-1055. https://doi.org/10.1016/j.jtcvs.2011.06.019

39. Shinn SH, Schaff HV. Evidence-based surgical management of acquired tricuspid valve disease. Nat Rev Cardiol 2013;10(4):190-203. https://doi.org/10.1038/nrcardio.2013.5

40. Cho WC, Park CB, Kim JB, Jung SH, Chung CH, Choo SJ, et al. Mechanical valve replacement versus bioprosthetic valve replacement in the tricuspid valve position. J Card Surg 2013;28(3):212-217.

https://doi.org/10.1111/jocs.12093
41. Asmarats L, Puri R, Latib A, Navia JL, Rodés-Cabau J. Transcatheter tricuspid valve interventions: landscape, challenges, and future directions. J Am Coll Cardiol 2018;71(25):29352956.

https://doi.org/10.1016/j.jacc.2018.04.031

\section{TRICUSPID REGURGITATION: ETIOLOGY, CURRENT DIAGNOSTIC AND TREATMENT OPTIONS}

\section{J. Krištopaitis, T. Joteika, Ž. Paškevičius}

Keywords: tricuspid regurgitation, cardiac surgery, valvular heart disease, transcatheter intervention.

Summary

Tricuspid regurgitation (TR) is a very important and often underappreciated valvular heart disease in cardiology practice. The main characteristic of TR is inverse blood flow from right ventricle to right atrium. TR can be primary (organic), secondary (functional) and isolated TR. Tricuspid regurgitation usually can be found accidentally during routine echocardiogram. First-line and the most widely usable radiological tests to diagnose TR and define degree of severity are transthoracic echocardiogram, transesophageal echocardiogram, but cardiovascular magnetic resonance imaging is still considered as a gold standard. Mild TR is considered benign pathology, but moderate or severe TR is associated with increased risk of negative outcomes and myocardial damage. Despite these data, few patients with significant TR undergo surgery. Traditional teaching that functional TR resolves on its own if the underlying disease is successfully treated has proven to be incorrect. As more and more patients undergo transcatheter correction of left heart valves, the development of functional TR has gained momentum. Many transcatheter devices are currently in an early phase of clinical trials, which early results are promising and could fundamentally change treatment options for high-risk patients with TR. This article will review the most common etiologies, current diagnostic methods, recent treatment guidelines and future treatment perspectives of TR.

Correspondence to: kristopaitisjustas@gmail.com

Gauta 2020-05-26 